\title{
Chronic Tophaceous Gout
}

SALIM DÖNMEZ, MD, Assistant Professor, Department of Rheumatology, Yuzuncu Yil University Medical Faculty, Van; ÖMER NURI PAMUK, MD, Professor, Department of Rheumatology, Trakya University Medical Faculty, Edirne, Turkey. Address correspondence to Dr. S. Dönmez, Yuzuncu Yil University Medical Faculty, Rheumatology, Van, Turkey. E-mail: drsalimdonmez@hotmail.com. J Rheumatol 2014;41:554-5; doi:10.3899/jrheum.130688

Severe tophaceous gout is associated with renal impairment, alcohol, obesity, diet, hypertension, family history, and low socioeconomic status ${ }^{1,2}$. Treatment failure is estimated in about $1 \%$ to $1.5 \%$ of cases of gout in the United States ${ }^{3}$.

Our patient was a 60 -year-old male with gouty arthritis for 15 years and chronic renal failure for 6 years. He described irregular usage of colchicine and urate-lowering drug for the last 15 years due to noncompliance with therapy. He used neither diuretics nor other prohyperuricemic drugs. Family history was nonsignificant for gout. On physical examination, he had massive and deforming tophi and active synovitis of bilateral small joints of the hands, wrists, elbows, knees, ankles, and ears (Figure 1). There were ulcerated lesions over the tophi in both ankles (Figure 2).

Laboratory data were as follows: uric acid, $8.1 \mathrm{mg} / \mathrm{dl}$; C-reactive protein (CRP): $7.5 \mathrm{mg} / \mathrm{dl}$; creatinine, $1.4 \mathrm{mg} / \mathrm{dl}$; radiographs of hands revealed erosions (Figure 3). Cultures from ulcerated lesions yielded no growth. The patient was confined to a wheelchair because of his severe arthritis. He could not tolerate colchicine because of severe diarrhea and did not want to use steroids. Therefore, the patient was started on interleukin-1 antagonist (anakinra) $100 \mathrm{mg} /$ day subcutaneously. At the end of the first week of therapy, his synovitis regressed significantly and he was able to walk without any support. Because his uric acid level was still high $(7.8 \mathrm{mg} / \mathrm{dl}$ ) with allopurinol (up to $450 \mathrm{mg}$ /day for 3 mos), he was given febuxostat $40 \mathrm{mg} /$ day.

After 4 months of therapy with anakinra and febuxostat, he had no active synovitis. He was able to get out of the wheelchair and his CRP $(0.4 \mathrm{mg} / \mathrm{dl})$ and uric acid $(4.2$ $\mathrm{mg} / \mathrm{dl}$, the target is $<5 \mathrm{mg} / \mathrm{dl}$ ) levels were normal. In addition, the ulcerated lesions improved, probably owing to control of the inflammation.

\section{REFERENCES}

1. Vázquez-Mellado J, Cruz J, Guzmán S, Casasola-Vargas J, Lino L, Burgos-Vargas R. Severe tophaceous gout. Characterization of low socioeconomic level patients from México. Clin Exp Rheumatol 2006;24:233-8.

2. Padang C, Muirden KD, Schumacher HR, Darmawan J, Nasution AR. Characteristics of chronic gout in Northern Sulawesi, Indonesia. J Rheumatol 2006;33:1813-7.

3. Dave AJ, Kelly VM, Krishnan E. Pegloticase and the patient with treatment-failure gout. Expert Rev Clin Pharmacol 2012;5:501-8.

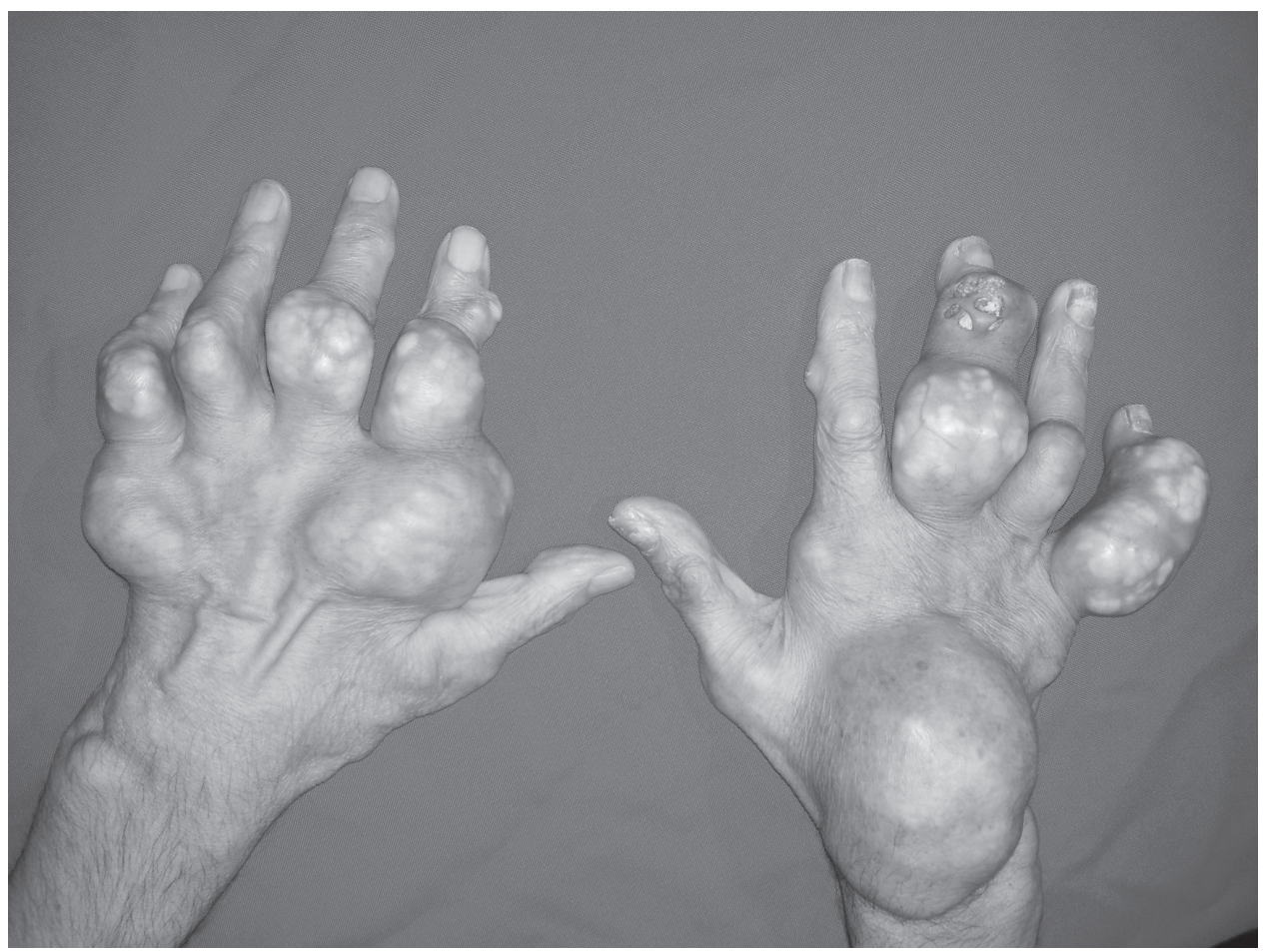

Figure 1. Multiple massive and deforming tophi of the hands. 


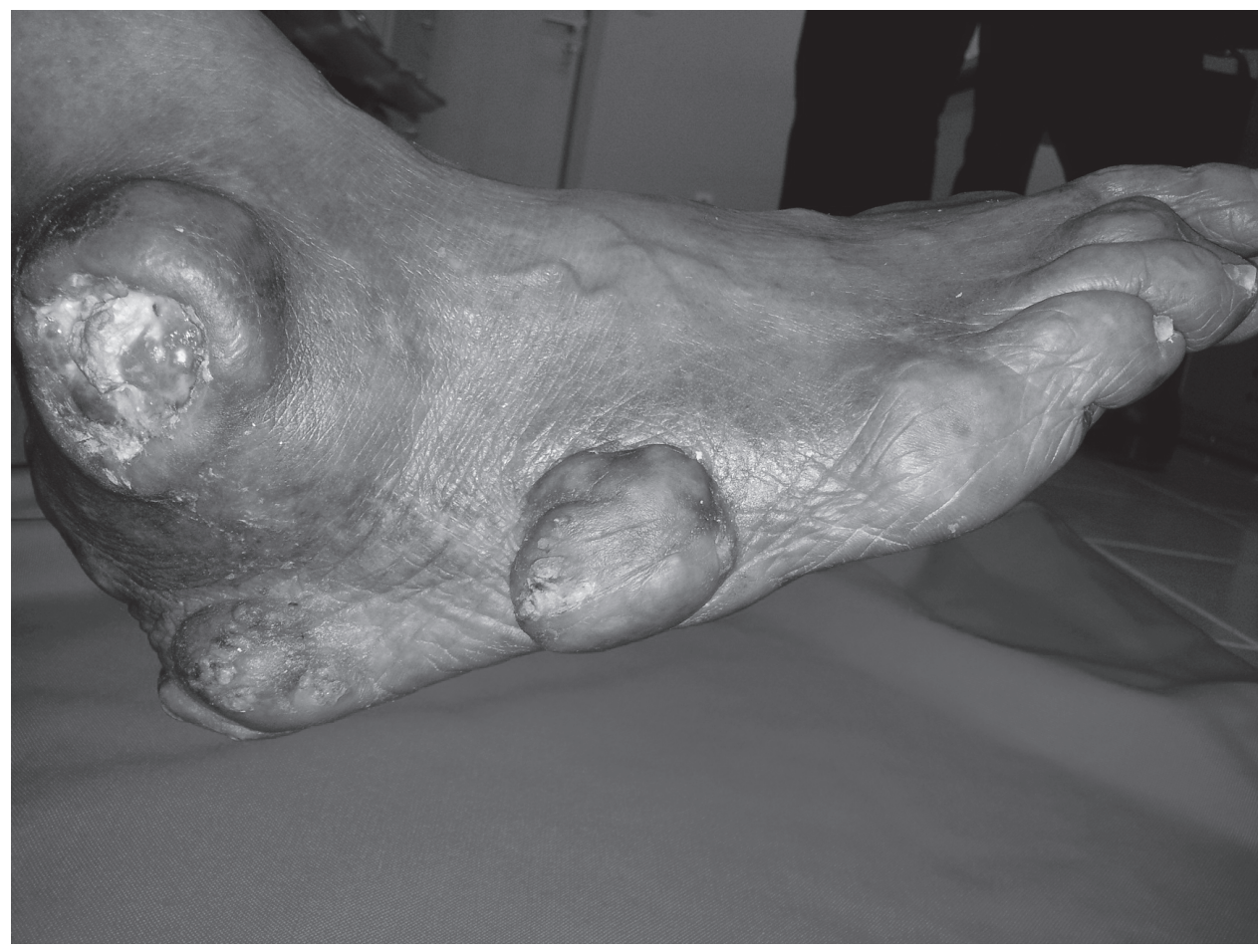

Figure 2. An ulcerated lesion over the ankle and tophi on feet.

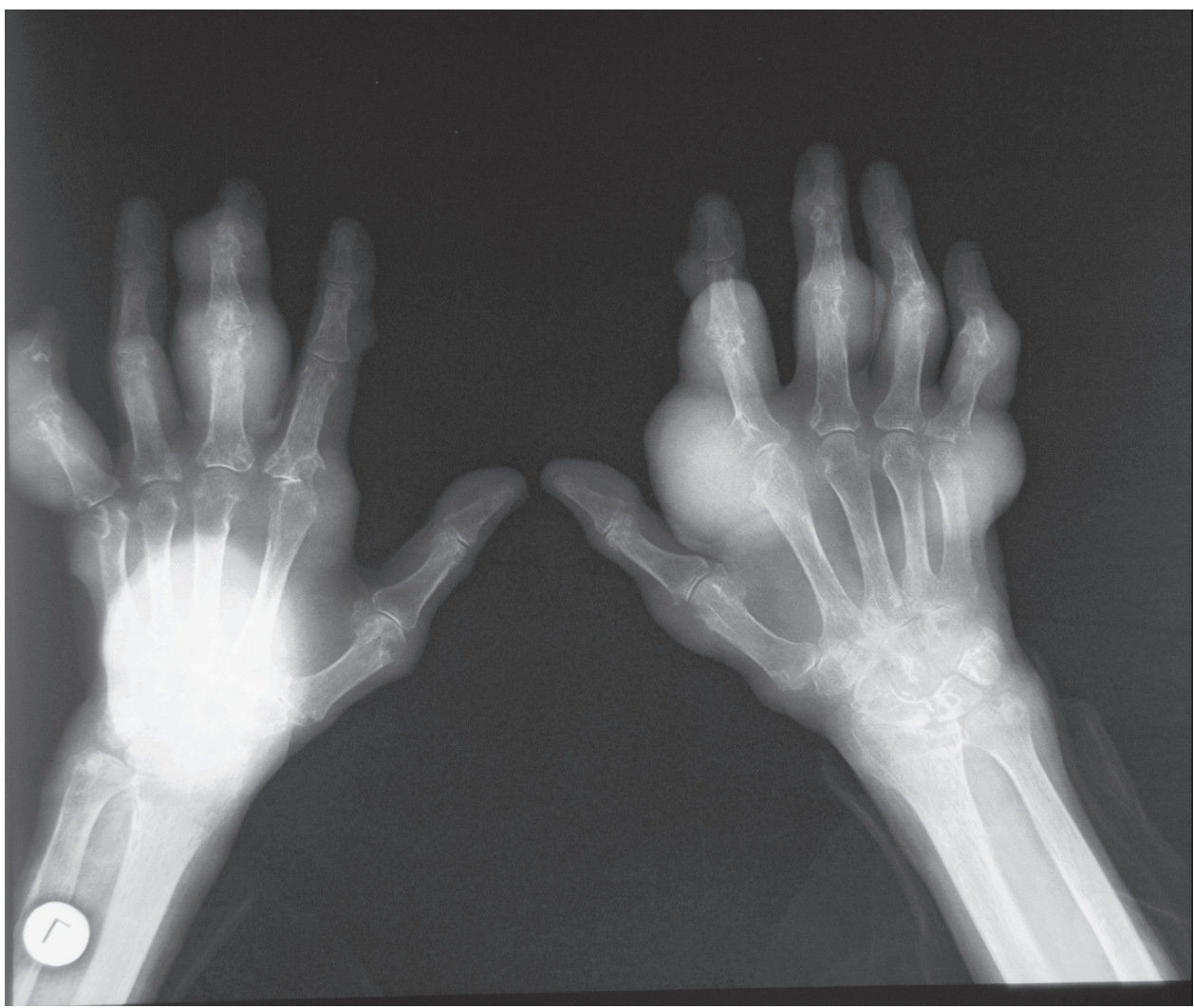

Figure 3. Radiographs of the hands showed classic punched-out erosions with overhanging edges, and calcification of tophaceous deposits. 